\title{
PSYCHOLOGICAL CORRELATES OF TRAUMATIC EXPERIENCES AND COPING STRATEGIES OF POST AMPUTATION: A CASE STUDY OF MULAGO SPECIALIZED NATIONAL HOSPITAL , KAMPALA UGANDA.
}

\author{
Journal of Mental Health@SJHR-Africa \\ KIZITO MUWONGE ${ }^{b, 4}$, FRANK PIO KIYING Ic,5 \\ a Department of Health Sciences, Uganda Martyrs University, \\ Kampala, Uganda. \\ Tel.: +256382410611 \\ b Department of Health Sciences, University of Kisubi, \\ Kisubi, Uganda. \\ Tel.: 0312225400 \\ c School of Social sciences, Nkumba University, \\ Lyamutundwe, Entebbe, Uganda. \\ Tel.: +256772446510
}

SULAIMAN MAHMOOD KAKOOZA ${ }^{a, 1,2}$, ZAITUNE NANYUNJA ${ }^{a, 3}$,

\footnotetext{
${ }^{1}$ Corresponding author.

${ }^{2}$ E-mail: kakoozasulaiman@gmail.com

${ }^{3}$ E-mail: nanyunjazai@gmail.com

${ }^{4}$ E-mail: kizitomm@gmail.com

${ }^{5}$ E-mail: kfrankpio@yahoo.com
} 
Abstract Background: The study assessed the effect of psychological correlates of traumatic experiences on coping strategies of post-amputation basing on evidence from Mulago specialized national hospital, Kampala-Uganda. It specifically analyzed the personality styles that enhance coping among amputees, assessed the psychological consequences among amputees, and examined the psychological interventions among amputees.

Methodology: The study adopted a hospital-based prospective post-treatment design employing a quantitative research approach. The quantitative data were collected using questionnaires from 72 patients who were admitted for amputations and attending weekly amputee clinics and those using prostheses and orthosises. The data was processed at both the descriptive and inferential levels using SPSS version 20.0 .

Results: The study found extraversion as a statistically positive correlate with the confrontational form of coping style $(r=0.279, p=0.031<0.05)$. It found a significantly positive correlate that enhanced planful problem solving $(r=0.278, p=0.032<0.05)$ and positive reappraisal $(r=0.301, p$ $=0.019<0.05$ ) compared to conscientiousness as a negative correlate of coping styles particularly self-control $(r=-0.326, p=0.011<0.05)$ and escape avoidance $(r=-0.263, p=0.043<0.05)$. Results showed abnormal depression (46.7\%), suffering abnormal anxiety (45.0\%) alongside demonstrating symptoms of at least 2 Post-Traumatic Stress Disorders (46.7\%) as the psychological consequences. The psychological interventions study found included specialized physician services (60.0\%), primary care provision (45.0\%) and financial assistance (46.7 among others

Conclusion and discussion: Personality styles of extraversion, agreeableness, and conscientiousness are crucial in the coping styles among amputees and therefore need to be well established and aligned with supporting initiatives. Administrative staff of specialized units needs to put in place workable measures like avoiding unfair self-blame and inculcating a belief that they are still worth as to help amputees to improve their self-esteem thereby minimizing adverse psychological consequences.

\section{Background}

Over the years, Uganda has been experiencing the heaviest burden of Orthopedic and head injuries from road traffic accidents (Balikuddembe et al., 2017). At present, over 28.9 deaths per 100,000 populations occur annually due to road traffic accidents (WHO, 2013). Although victims survive, many of them however remain with severe damages and injuries on their bodies. Nevertheless, shared experiences due to traumatic events and after amputation, gave insight into the kind of life amputated victims are going through including, psychological torture, loss of employment, body image loss among others. To have a deeper insight, efforts were made to dedicate a scheme to the lives of individuals after amputation.

In the present society, several people have experienced limb loss for one or more reasons resulting in a total change of body image (Okello et al., 2019). Loss of a limb is a tragic event and in many circumstances, amputation cannot be avoided. Amputation involves a change in the body structure (Burger \& Marincek 2007). At the same time, amputation has got a great influence on many activities; participation in various activities that people used to do can be retarded hence affecting the quality of life of victims economically, socially, and psychologically. Peoples' lifestyles are forced to change; due to disability caused by amputation, sources of earning a living are partially or badly affected (Mugo, 2010). Although stump problems disrupt the day-to-day use of artificial limbs, (Salawu et al., 2006) urge that good clinical practices and psychoeducation services aid continued use of prosthetic limbs with a significant reduction in psychological illness observed in various studies (Srivastava, 2010; Mugo, 2010; Bessell et al., 2012).

According to (Dieter et al., 2017) Amputation entails the removal of various body parts that leaves an individual physically incapacitated. An early researcher such as Padula and Friedmann (1987) asserts that amputation practices have been proficient since 43,000 BCE mainly for ritualistic and vocational reasons. However, amputation practices with prostheses made of fiber, wood, bone, and metals, often lined with rags, started as early as 1,500 BCE to cater for punitive and curative reasons, about ritualistic and vocational reasons. 
Worldwide, more than 900,000 people are living with minor limb loss (Amoah, 2018), as a result of ways of life, amputation continues to be a major health problem among adults (Kathryn et al.,2018). According to (Kakra et al.,2018), more than 2 million people in the United States live with amputations equivalent to 185,000 amputations occurring each year. In the US, 54\% of amputations are due to non-traumatic reasons, such as diabetes, peripheral artery disease, and Less than $2 \%$ of amputations are related to cancer (Ramirez \& Menaker, 2017). While $45 \%$ is a result of trauma which is one of the leading causes of death and disability in many LMICs, Uganda is no different (Amputee Coalition of America, 2014).

Although persons with physical disabilities have been assisted to participate in society through the provision of technologies such as prosthetic limbs and orthotic bracing devices, the relationship between coping in the present trauma and they're psychological well- being has not induced keen interest to care, providers, while amputation also leads to emotional and physical distress (Srivastava et al., 2010).

Amalraj et al.,(2017) highlight a direct connection of one's' body image with psychological adjustment. According to Anna et al., (2016), the changes in appearance that many people endure as a result of trauma or disease can completely alter one's pre-existing body image and take him or her far from his ideal body image (Anna, 2016). Independent of the cause of amputation, whether it is due to vascular, traumatic, or orthopedic causes, it is a mar surgery that affects the lives of these patients. According to Kalpana et al., (2014), the dynamic construction is subject to revision and reconstruction in response to both internal and external stimuli. In Uganda, several amputees have failed to appreciate the use of prostheses as a perfect answer to their challenge of lacking a limb or limbs. This is attributed to psychological problems associated with their use (Orthopedic report, Kiruddu General Referral Hospital, 2017). The affected individuals have abandoned the prosthetic devices due to the discomfort. Therefore, this research sought to assess the relevance of clinical counseling on post amputated individuals using prostheses and orthosises.

\section{Study Scope}

\section{Geographical scope}

The study was carried out at the orthopedic ward in Mulago Specialized National Hospital in Kampala district Uganda.

\section{Content Scope}

The study focused on Psychological correlates and Coping strategies. The independent variable is Psychological correlates being characterized by personality style, psychological consequences; anxiety, depression levels, and PTSDs while the dependent variable which is coping strategies being reflected by Confrontation, distancing, self-control, seeking social support, positive reappraisal, escape avoidance, and planful problem solving

\section{Time Scope}

The study was carried out for a period of 4 months from March 2019 to July 2019. simply because the researcher intended to accomplish this study within the institution's academic calendar.

\section{Limitations of the study}

The researcher focused mainly on adult amputees not considering children who are also victims.

However, this was due to the failure of children to express their feeling as they were considered in the pre-test.

\section{Study design}

\section{METHODOLOGY}

The study was a hospital-based prospective post treatment study employing quantitative research approaches with descriptive and correlative research design for collecting and analyzing data. This was done for data description and interpretation of information. The data collection and research activities tend to narrow to particular sites, subjects, materials, topics, questions, and themes, to study extensively the background, current status, and environmental interactions of a given organizational unit; an individual, group, institution, or community. 
The study was quantitative in that the researcher sought inquiries on the problem based on testing the variables, measure with numbers, and analyzing with statistical procedures. It was also correlative because it sought to establish the relationship between personality styles and coping strategies among amputees in Mulago National Specialized Hospital (MNSH) Kampala District, Central Uganda.

\section{Study site}

This study was conducted in Mulago National Specialized Hospital (MNSH) located in Kampala District, Central Uganda. Mulago National Specialized Hospital has been selected for this study because it is the major hospital where orthopedic rehabilitation services are provided in Uganda. Secondly, Mulago National Specialized Hospital has a cosmopolitan population being the country's capital city and surrounded by densely populated districts of Wakiso and Mukono. This makes Mulago handle numerous amputations. Approximately $90 \%$ of the country's amputations are attributed to motorbike accidents in the city locally known as Boda Bodas which people use to avoid city traffic jams.

\section{Study population}

The study population in this case comprised of patients who have undergone amputation in Mulago National Referral hospital. A total of 89 clients are amputated annually per 1500 patients received annually (Gakwaya, 2005).

\section{Inclusion criteria}

These included patients who had been clinically examined and were amputated, patients attending weekly amputee clinics, and amputees fitted with prostheses and orthosises.

\section{Exclusion criteria}

Patients who do not want to participate in the study after being explained about the nature and purpose of the study. Patients with a history of psychiatric disorders and associated physical disabilities other than amputation were excluded from the study.

Sample size determination

From the study population of 88 patients who are amputated annually, a sample of 72 patients was obtained and recruited into the study as shown below. From the study population, the sample size was estimated using the formula $n=4 p q / L 2$ (Krejcie and Morgan 1970).

Where:

$\mathrm{n}=$ sample size required

$p=e s t i m a t e d$ number of amputees

$q=1-p$

$\mathrm{L}=$ desired errors (required precision).

Estimated value of $p=81 \%$

Desired error $=10 \%=0.1$

$$
\begin{gathered}
\mathrm{n}=4 \times 0.81(1-0.81) \\
0.12
\end{gathered}
$$

$$
\mathrm{n}=72
$$

Thus a sample size of 72 was used.

Sampling techniques

The study used a simple random sampling technique to select 72 respondents (male and female) to collect data. At the same time, consecutive sampling of patients was also used for those attending weekly amputee clinics and those using prostheses and orthosises until the required number was obtained.

\section{Research Instruments}

\subsection{Sampling frame}

These are tools used for data from the field. In this study, the researcher used the questionnaire (Performa sheet) to elicit for socio-demographic characteristics of respondents and assess for the psychological intervention. On another hand, standardized tools were used to assess for other independent variables in the study including anxiety, depression, and PTSD. This study used the Big five inventory for the personality test, Hospital Anxiety, and Depression Scale (HADS), DSM V, and Ways of Coping Questionnaire for data collection. 
Table 1.

\begin{tabular}{llll}
\hline Category of respondents & population & sample & Sampling technique \\
Male amputees & 64 & 52 & Simple random/ consecutive sampling \\
Female amputees & 24 & 20 & Simple random \& consecutive \\
Total & 88 & 72 & \\
\hline
\end{tabular}

\section{Self -administered Performa Sheet}

This sheet was designed by the investigator to collect data relevant to socio-demographic characteristics such as age, sex, marital status, cause of amputation among others. Data were collected postoperatively within 2-3 weeks

Big five Personality Inventory (BFI)

Personality traits were measured based on the Big Five model, using the Big Five Inventory (BFI). This questionnaire was developed by McCrae and Costa (1995) as a guide to discovering one's personality traits. This method comprises 44 items (adjectives) referring to specific individual characteristics, e.g., extraverted, enthusiastic. Respondents had to evaluate each item using a 5-point scale ranging from $1=$ Disagree strongly, to 5 = Agree strongly. Each of the five personality dimensions (Extraversion, Agreeableness, Conscientiousness, Emotional Stability, and Openness to Experience). A score of 5 indicates "Yes", you strongly agree with the statement, and 1 indicates "No", you strongly disagree with it

\section{Hospital Anxiety and Depression Scale (HADS)}

The study used the Hospital anxiety and depression scale (HADS) to determine anxiety and depression levels among amputees. The HADS has two subscales: the anxiety subscale (HADS-A) and the depression subscale (HADS-D). Each subscale contains seven items for a total of 14 items in the HADS. The reliability of HADS was found to have Cronbach's $\alpha$ for the total HADS, the HADS-A and HADS-D of $0.78,0.73$, and 0.76 respectively. It has cutoff point $\geq 8$ for each subscale to be positive for anxiety and depression

\section{Ways of Coping Questionnaire (WCQ):}

This tool was developed by Lazaus and Folkman (1988). It was designed to assess the patient thoughts and actions in dealing with stressful incidents in their social life. It consists of 66 items designed to measure 8 different coping strategies namely; confrontive coping, distancing, self-controlling, seeking social support, accepting responsibility, escape avoidance, planful problem solving, and positive reappraisal. The first four coping methods measure emotion-focused coping and the rest measure problem-focused coping. The original scale, responses were measured on a 4-point Likert scale with response options of doesn't apply/not used at all (1), used somewhat (2), used quite a bit (3), and used a great deal (4). It was modified in this current study WCQ into three-point Likert Scale: with the following responses scoring doesn't apply/not use at all (1), used a little bit (2), and always used (3). The current study followed the same system, a high score indicates greater use of that particular coping strategy.

\section{Quality Control}

\section{Pretest}

In this present study, the researcher pre-tested the questionnaire before data collection to enhance its validity. The pretest was done to determine the comprehensibility of the questions, the ability of the questions to elicit the required data and to detect any ambiguity in the questions.

\section{Validity}

Validity refers to the appropriateness of the instrument or validity is the extent to which research results can be accurately interpreted and generalized to other populations. The researcher with the help of the supervisor used the content validity index (CVI) which was a scale developed by computing relevant items in the questionnaire. This was done by employing the following formula:

$C V I=$ Number of valid items $X 100$

Total of number of items 


\subsubsection{I= 66/66, $=1 / 1=100=099$}

The results obtained a 0.99 which was above 0.6 figured by the researcher which was then taken as a valid instrument as considered valid by (Amin, 2005)

\section{Reliability}

Reliability of data refers to whether repeating the same measurement under similar conditions yields the same results (Kumar 1990). The reliability of the questionnaires was improved through pretesting of pilot samples from the field by issuing 20 questionnaires which enabled the rephrasing of some questions. Data were entered into a statistical package for social scientists (SPSS) to determine the reliability of a tool. Cronbanch alpha coefficient (2004) was used to assess internal consistency. The score turned out to 0.8 and then the instruments were considered reliable for the study.

Reliability table

\section{Cronbach's alpha \\ No of items \\ .8222}

66

Data collection procedure

The student got an introduction letter from the dean school of the postgraduate which was presented to the management of the Mulago orthopedic department through the Mulago research management team. Upon authorization, the student was issued an acceptance letter that introduced him to staff and clients at the orthopedic wards.

With the help from the management at the orthopedic ward, the student-constructed a sampling frame that helped him identify patients to be contacted during data collection.

The student then embarked on data collection with the help of three research assistants (staff) from the orthopedic department having sought consent from respondents and explaining to them the purpose of the study while ensuring confidentiality. Since a given portion of the target population was illiterate and semi-literate, consideration was made in such cases and the questionnaires were administered and Patients were interviewed individually by the researcher and the trained health professional (research assistants) and questionnaires were filled on behalf of the respondents, to elicit data on the requires socio-demographic factors, available interventions and other variables about the study objectives.

\section{Statistical Data Analysis}

After collecting data, it was edited, coded, and entered into the computer using the statistical package for social scientists (SPSS) version 16. Editing was done during and after data collection, whereby the student had to make sure that the exact number of questionnaires administered are returned to detect abnormalities that could have risen.

Coding was done by assigning numerical and alphabetical numbers to responses in the questionnaire. Pre-coding was done by assigning numbers in some sections of the questionnaire. Post coding was done after fieldwork to assign numbers to open -ended responses in form of suggestions from respondents.

Data entry was done using a statistical package for social scientists (SPSS) to put responses for the possibility of producing necessary statistics during analysis.

Data cleaning was done by removing irrelevant information from the questionnaire to minimize mistakes in statistical output.

Descriptive statistics such as Frequencies and percentages were used to analyze objectives 2 and 3 . Inferential statistics; Pearson's correlation coefficient was used for objective 1 to test for the relationship between personality style and coping strategies of post-amputation. The study took 0.05 as a standard level of rejecting or accepting the hypothesis.

Ethical Considerations

\section{Permissions}

Before going into the field to collect data, the researcher first obtained an introductory letter from the Faculty of Health Sciences, Uganda Martyrs University through Uganda Martyr's university ethical review committee. Authorization was then obtained from the Mulago Department of Orthopaedics. 
Table 2.

\begin{tabular}{llll}
\hline Demographic characteristic & Frequency(N = 60) & Percentage (\%) \\
\hline Age in years & $18-25$ & 14 & 23.3 \\
& $26-35$ & 24 & 40.0 \\
& $36-45$ & 11 & 18.3 \\
Gender & Above 45 & 11 & 18.3 \\
& Male & 39 & 65.0 \\
Marital status & Female & 21 & 35.0 \\
& Married & 20 & 33.3 \\
& Not married & 30 & 50.0 \\
\multirow{4}{*}{ Education level } & Divorced/separated & 3 & 5.0 \\
& Widowed & 7 & 11.7 \\
& None & 4 & 6.7 \\
& Primary & 8 & 13.3 \\
& Secondary & 24 & 40.0 \\
Current working status & Yes & 24 & 40.0 \\
& Nertiary & 21 & 35.0 \\
& No & 39 & 65.0 \\
\hline
\end{tabular}

\section{Study Benefits and Risks}

The participants were informed of the benefits related to this study. The participants were informed that the study had no risks associated with one's participation.

\section{Informed Consent}

Informed consent of the study participants was sought before data collection by verbal consent in both English and Luganda. The objectives of the study were discussed with participants.

The information obtained from the participants was kept with the utmost confidentiality. The names of the participants were not included in the questionnaire but rather unique codes were considered.

\section{The Right to Self-Determination}

The principle of self-determination means that prospective participants have the right to decide voluntarily whether to participate in a study, without risking any penalty or prejudicial treatment (Polit\& Beck, 2008). In this research, respondents were treated as 'autonomous agents'

\section{Justice}

In this study, the selection of the sample was conducted according to the eligibility criteria where the researcher ensured that the respondents have the right to fair treatment before, during, and after they participate in the study. The researcher also ensured that the respondents' privacy was maintained throughout the study.

\section{RESULTS AND ANALYSIS OF FINDINGS}

\section{Response Rate}

The study as was the original plan targeted a total of 72 amputees as respondents but received complete responses from 60 who were patients admitted for amputations. This meant that the study received an $83.3 \%$ response rate which was considered sufficient to address the research objectives.

\section{Demographic characteristics}

The demographic characteristics considered included sex, formal education level, age, and marital status of the patients attending to amputee clinic. The descriptive results in this regard were as presented in Table 3 below.

\subsection{Table 4.1: Demographic characteristics of the amputees}

\section{Source: Primary 2019}


Table 3.

\begin{tabular}{|c|c|c|c|}
\hline \multicolumn{2}{|c|}{ Traumatization and amputation aspects } & \multirow{2}{*}{$\begin{array}{l}\text { Frequency }(\mathrm{N}= \\
60) \\
26\end{array}$} & \multirow{2}{*}{$\begin{array}{l}\text { Percentage } \\
\text { (\%) } \\
43.3\end{array}$} \\
\hline Time period when & Months ago & & \\
\hline Traumatic event & 1-3years ago & 26 & 43.3 \\
\hline occurred & More than 3 years ago & 8 & 13.3 \\
\hline Time period of & Months ago & 31 & 51.7 \\
\hline \multirow[t]{2}{*}{ amputation } & 1-3years ago & 24 & 40.0 \\
\hline & More than 3 years ago & 5 & 8.3 \\
\hline \multirow{6}{*}{$\begin{array}{l}\text { Type of } \\
\text { amputation }\end{array}$} & both lower limbs & 2 & 3.3 \\
\hline & left arm & 1 & 1.7 \\
\hline & lower limb & 47 & 78.3 \\
\hline & Right arm & 1 & 1.7 \\
\hline & upper arm & 1 & 1.7 \\
\hline & Upper Limb & 8 & 13.3 \\
\hline \multirow{4}{*}{$\begin{array}{l}\text { Cause of } \\
\text { amputation }\end{array}$} & Accident & 43 & 71.7 \\
\hline & Amunition(Bomb, Land mine) & 2 & 3.3 \\
\hline & Chronic Illness(Diabetes, Cancer) & 11 & 18.4 \\
\hline & $\begin{array}{l}\text { Others(Infection, Mob Justice, Extraction machine, } \\
\text { Bite) }\end{array}$ & 4 & 6.7 \\
\hline
\end{tabular}

Table 4.1 above shows that most of the amputees were aged in the youthful age of 26 to35 years $24(40.0 \%)$ compare to the minority who were either aged 36 to 45 years $11(18.3 \%)$ or above $45 y e a s r$ $11(18.3 \%)$. The results also show that most of the respondent amputees were male $39(65.0 \%)$, not married $30(50.0 \%)$, and with the highest education level of either secondary $24(40.0 \%)$ or tertiary $24(40.0 \%)$. As presented in the table above, most of the amputees were not working 39(65.0\%). These demographic results show how adequate the study has addressed the various psychological situations manifested since the varied views representative of all categories found in the population were included.

The descriptive results about when the traumatic events occurred, when amputation took place, and their respective causes are presented in table 4.2 below;

\subsection{Table 4.2 Traumatic events, types and their causes}

\section{Source: Primary 2019}

Results about the traumatic events show that most of the amputees had experienced traumatic events that occurred to them 1 to 3years ago 26(43.3\%) compared to the minority who had experienced the event more than 3 years ago $8(13.3 \%)$. Most of the amputees as seen in the table above were of the lower limb $47(78.3 \%)$ followed by the upper limb8 (13.3\%) with the least in the left arm 1(1.7\%), right arm 1(1.7\%), and upper arm 1(1.7\%).

Results additionally show that as accidents 43 (71.7\%) as the most common cause of the amputation, followed by chronic Illnesses like Diabetes and Cancer 11 (18.4\%) with the least cause as ammunition particularly the bomb and or land mines 2(3.3\%). This finding shows that a diversity of causes explains amputations and while some can be unavoidable some have to show at some later times of life specifically the chronic conditions.

\subsection{The personality styles that enhance coping among amputees in Mulago specialized national hospital, Kampala-Uganda}

The first objective of this study was to analyze the personality styles that enhance coping among amputees in Mulago Specialized national hospital, Kampala-Uganda. To attain this objective, descriptive results about 
Table 4.

\begin{tabular}{llll}
\hline Personality styles & & Frequency $\mathbf{( N = 6 0 )}$ & Percentage (\%) \\
Extraversion & Less & 12 & 20.0 \\
& Fair & 41 & 68.3 \\
\multirow{4}{*}{ Agreeableness } & More & 7 & 11.7 \\
& Less & 9 & 15.0 \\
\multirow{2}{*}{ Conscientiousness } & Fair & 30 & 50.0 \\
& More & 21 & 35.0 \\
Neuroticism & Less & 11 & 18.3 \\
& Fair & 37 & 61.7 \\
& More & 12 & 20.0 \\
Openness & Less & 12 & 20.0 \\
& Fair & 31 & 51.7 \\
& More & 17 & 28.3 \\
& Less & 6 & 10.0 \\
& Fair & 44 & 73.3 \\
\hline
\end{tabular}

the personality styles alongside coping among amputees in Mulago specialized national hospital were first presented as shown in table 4.3 and table 4.4 below. Thereafter the personality styles and coping approaches were subjected to Pearson Correlational analysis and results were presented in table 4.5 below.

\subsection{Table 4.3: The personality styles among amputees attending Mulago specialized national hospital}

\section{Source: Primary 2019}

above shows most of the amputees attending Mulago specialized national hospital scoring moderately on all the personality styles that extraversion $41(68.3 \%)$, agreeableness $30(50.0 \%)$, conscientiousness 37(61.7\%), neuroticism 31(51.7\%) and openness 44(73.3\%). The study results however show that personality style of most manifested as agreeableness $21(35.0 \%)$ followed by Neuroticism 17(28.3\%), then openness $10(16.7 \%)$ as compared to extraversion $7(11.7 \%)$ as the least amongst the amputees attending Mulago specialized national hospital.

The study was a way of establishing the personality styles that enhance coping among amputees in Mulago specialized national hospital additionally established the coping styles adopted by the respondent amputees. The descriptive results in this regard were as presented in table 4.5 below;

\subsection{Table 4.4: The coping styles demonstrated among amputees attending Mulago specialized national hospital}

\section{Source: Primary 2019}

The study results show the often demonstrated coping styles amongst amputees as positive appraisal $17(28.3 \%)$ then followed by distancing $15(25.0 \%)$. The other coping styles often include seeking social support 12(20.0\%), planful Problem solving $10(16.7 \%)$, accept responsibility $8(13.3 \%)$ and escape avoidance $8(13.3 \%)$. The study results show confrontational coping style $6(10.0 \%)$ as the least demonstrated amongst the amputees attending Mulago Specialized Unit. This means that a diversity of coping styles manifest amongst the amputees.

Table 4.5 Correlational Results for the personality styles that enhance coping among amputees in Mulago specialized national hospital

above shows that openness and neuroticism are not statistically significant correlates that enhance coping styles amputees in Mulago specialized national hospital $(p>0.05)$. The results in Table 4.4 suggest 
Table 5.

\begin{tabular}{|c|c|c|c|}
\hline Coping styles & & Frequency $(N=60)$ & Percentage (\%) \\
\hline \multirow[t]{3}{*}{ Confrontational } & Rarely & 24 & 40.0 \\
\hline & Sometimes & 30 & 50.0 \\
\hline & Often & 6 & 10.0 \\
\hline \multirow[t]{3}{*}{ Distancing } & Rarely & 31 & 51.7 \\
\hline & Sometimes & 14 & 23.3 \\
\hline & Often & 15 & 25.0 \\
\hline \multirow[t]{3}{*}{ Self-control } & Rarely & 33 & 55.0 \\
\hline & Sometimes & 20 & 33.3 \\
\hline & Often & 7 & 11.7 \\
\hline \multirow[t]{3}{*}{ Seeking social support } & Rarely & 28 & 46.7 \\
\hline & Sometimes & 20 & 33.3 \\
\hline & Often & 12 & 20.0 \\
\hline \multirow[t]{3}{*}{ Accept responsibility } & Rarely & 33 & 55.0 \\
\hline & Sometimes & 19 & 31.7 \\
\hline & Often & 8 & 13.3 \\
\hline \multirow[t]{3}{*}{ Escape avoidance } & Rarely & 30 & 50.0 \\
\hline & Sometimes & 22 & 36.7 \\
\hline & Often & 8 & 13.3 \\
\hline \multirow[t]{3}{*}{ Planful Problem solving } & Rarely & 28 & 46.7 \\
\hline & Sometimes & 22 & 36.7 \\
\hline & Often & 10 & 16.7 \\
\hline \multirow[t]{3}{*}{ Positive reappraisal } & Rarely & 35 & 58.3 \\
\hline & Sometimes & 8 & 13.3 \\
\hline & Often & 17 & 28.3 \\
\hline
\end{tabular}

that extraversion as a personality style has got a statistically positive correlate with the confrontational form of coping style demonstrated among the respondent amputees in Mulago specialized national hospital $(r=0.279, p=0.031<0.05)$. The result implies that amputees who score high on extraversion as a personality style are mostly confrontational in copying with situations than those who score less on extraversion.

above shows that agreeableness as a personality style has similarly got a significantly positive correlate withplanful problem solving $(r=0.278, p=0.032<0.05)$ and positive reappraisal $(r=0.301, p=0.019<0.05)$ as a coping strategy. The result means that amputees who score high on agreeableness as a personality style mostly demonstrate planful problem solving alongside reappraisal and vice versa.

Lastly findings shown above indicates that conscientiousness as a personality style significantly a negative correlate with coping styles particularly self-control $(r=-0.326, p=0.011<0.05)$ and escape avoidance $(r=-0.263, p=0.043<0.05)$. The finding means that demonstration of high conscientiousness as a personality style lowers self-control and escape avoidance and vice versa.

\subsection{The psychological consequences among amputees in Mulago specialized national hospital, Kampala-Uganda}

The second objective of the study was to determine psychological consequences among amputees in Mulago specialized national hospital, Kampala-Uganda. In the study, the amputees were asked as to rate the different aspects of the psychometric tools for psychological conditions as it applies to them. The descriptive results in this regard were as presented in table 4.4 below. 
Table 6.

\begin{tabular}{|c|c|c|c|c|c|c|c|c|}
\hline \multirow[b]{2}{*}{$\begin{array}{l}\text { Personality } \\
\text { styles }\end{array}$} & \multicolumn{8}{|c|}{ Coping Styles } \\
\hline & $\begin{array}{l}\text { Con- } \\
\text { fronta- } \\
\text { tional }\end{array}$ & $\begin{array}{l}\text { Dis- } \\
\text { tanc- } \\
\text { ing }\end{array}$ & $\begin{array}{l}\text { Self- } \\
\text { Control }\end{array}$ & $\begin{array}{l}\text { Seeking } \\
\text { social } \\
\text { support }\end{array}$ & $\begin{array}{l}\text { Accept } \\
\text { responsi- } \\
\text { bility }\end{array}$ & $\begin{array}{l}\text { Escape } \\
\text { avoid- } \\
\text { ance }\end{array}$ & $\begin{array}{l}\text { Planful } \\
\text { Problem } \\
\text { solving }\end{array}$ & $\begin{array}{l}\text { Positive } \\
\text { reap- } \\
\text { praisal }\end{array}$ \\
\hline Pearson & $0.279^{*}$ & 0.219 & -0.085 & -0.068 & -0.060 & -0.055 & & -0.092 \\
\hline $\begin{array}{l}\text { Correla- } \\
\text { Extraversion } \\
\text { tion }\end{array}$ & & & & & & & & \\
\hline $\begin{array}{l}\text { Sig. } \\
\text { (2-tailed) }\end{array}$ & $0.031 * *$ & 0.093 & 0.518 & 0.608 & 0.650 & 0.674 & 0.075 & 0.487 \\
\hline $\mathrm{N}$ & 60 & 60 & 60 & 60 & 60 & 60 & 60 & 60 \\
\hline $\begin{array}{l}\text { Pearson } \\
\text { Correla- } \\
\text { Agreeableness } \\
\text { tion }\end{array}$ & 0.061 & 0.059 & -0.003 & 0.207 & 0.018 & -0.110 & $0.278^{*}$ & $0.301^{*}$ \\
\hline $\begin{array}{l}\text { Sig. } \\
\text { (2-tailed) }\end{array}$ & 0.645 & 0.655 & 0.980 & 0.113 & 0.894 & 0.403 & $0.032 * *$ & $0.019 * *$ \\
\hline $\mathrm{N}$ & 60 & 60 & 60 & 60 & 60 & 60 & 60 & 60 \\
\hline Pearson & -0.029 & 0.014 & - & 0.140 & -0.153 & $-0.263^{*}$ & 0.083 & 0.105 \\
\hline $\begin{array}{l}\text { Con-Correla- } \\
\text { sci- tion }\end{array}$ & & & $0.326^{*}$ & & & & & \\
\hline $\begin{array}{l}\text { en- Sig. } \\
\text { tiou\$2-tailed) }\end{array}$ & 0.825 & 0.916 & $0.011 * *$ & 0.285 & 0.245 & $0.043^{* *}$ & 0.527 & 0.423 \\
\hline$-\quad N$ & 60 & 60 & 60 & 60 & 60 & 60 & 60 & 60 \\
\hline nessPearson & -0.015 & - & 0.017 & -0.143 & 0.190 & -0.010 & -0.007 & 0.189 \\
\hline $\begin{array}{c}\text { Correla- } \\
\text { Opennness } \\
\text { tion }\end{array}$ & & 0.019 & & & & & & \\
\hline $\begin{array}{l}\text { Sig. } \\
\text { (2-tailed) }\end{array}$ & 0.907 & 0.883 & 0.897 & 0.277 & 0.146 & 0.937 & 0.960 & 0.149 \\
\hline $\mathrm{N}$ & 60 & 60 & 60 & 60 & 60 & 60 & 60 & 60 \\
\hline Pearson & -0.192 & - & -0.016 & -0.161 & 0.082 & 0.160 & -0.218 & -0.225 \\
\hline $\begin{array}{l}\text { Correla- } \\
\text { Neuroticism } \\
\text { tion }\end{array}$ & & 0.005 & & & & & & \\
\hline $\begin{array}{l}\text { Sig. } \\
\text { (2-tailed) }\end{array}$ & 0.141 & 0.970 & 0.905 & 0.219 & 0.535 & 0.223 & 0.095 & 0.084 \\
\hline $\mathrm{N}$ & 60 & 60 & 60 & 60 & 60 & 60 & 60 & 60 \\
\hline
\end{tabular}

Table 7.

\begin{tabular}{llll}
\hline Psychological consequences & Frequency(N = 137) & Percentage (\%) \\
\hline Depression & Normal & 11 & 18.3 \\
& Borderline case & 21 & 35.0 \\
\multirow{4}{*}{ Anxiety } & Abnormal & 28 & 46.7 \\
& Normal & 13 & 21.7 \\
& Borderline case & 20 & 33.3 \\
\multirow{4}{*}{ PTSDs } & Abnormal & 27 & 45.0 \\
& None & 21 & 35.0 \\
& Atleast 1 & 11 & 18.3 \\
& Atleast 2 & 28 & 46.7 \\
\hline
\end{tabular}


Table 8.

\begin{tabular}{clllll}
\hline $\begin{array}{l}\text { Psychological interven- } \\
\text { tions }\end{array}$ & Poor $\mathbf{N}(\%)$ & Satisfactory $\mathbf{N}(\%)$ & Excellent $\mathbf{N}(\%)$ & \\
$\quad$ Support groups & $18(30.0)$ & $16(26.7)$ & $1(1.7)$ & $19(31.7)$ & $6(10.0)$ \\
Financial assistance & $23(38.3)$ & $28(46.7)$ & $1(1.7)$ & $7(11.7)$ & $1(1.7)$ \\
Counseling Services & $28(46.7)$ & $3(5.0)$ & $0(0.0)$ & $26(43.3)$ & $3(5.0)$ \\
Primary Care Provider & $23(38.3)$ & $27(45.0)$ & $1(1.7)$ & $7(11.7)$ & $2(3.3)$ \\
Specialized Physicians & $12(20.0)$ & $36(60.0)$ & $8(13.3)$ & $0(0.0)$ & $4(6.7)$ \\
Therapy Providers & $13(21.7)$ & $16(26.7)$ & $0(0.0)$ & $26(43.3)$ & $5(8.3)$ \\
\hline
\end{tabular}

\subsection{Table 4.6: The psychological consequences among amputees in Mulago specialized national hospital}

\section{Source: Primary 2019}

The study results are presented in the table above shows that most of the respondents amputees were abnormally depressed $28(46.7 \%)$ followed by a significant proportion of them that were at the borderline of suffering depression $21(35.0 \%)$. From the table only $11(18.3 \%)$ of the respondent amputees who constitute the minority was found to be normal.

Other results as presented from the table above indicates that most of the amputees were suffering abnormally from anxiety 27 (45.0\%) followed by a significant proportion of them that were at the borderline of suffering an anxiety disorder 20 (33.3\%). As can be seen in the table, only 13(21.7\%) of them were free of anxiety as a psychological consequences.

The study results lastly show that only $21(35.0 \%)$ of the respondent amputees who constituted the minority had no symptoms of Post-Traumatic Stress Disorder. Table 4.2 however indicates that the majority of the respondent amputees that were attending Mulago specialized national hospital had symptoms of at least 2 Post-Traumatic Stress Disorders 28(46.7\%). Results additionally show that up to 11(18.3\%) of the amputees that were attending Mulago specialized national hospital had symptoms of at least 1 Post-Traumatic Stress Disorder. The forgoing results illustrate how unaware the amputees are in as far as controlling feeling which could worsen their quality of life and demonstrates the need for programs that minimize such psychological consequences.

\subsection{The psychological interventions among amputees in Mulago specialized national hospital, Kampala-Uganda}

This study as its third objective was set to examine the psychological interventions among amputees in Mulago specialized national hospital, Kampala-Uganda. To address this objective, descriptive results were processed and presented as illustrated in Table 4.5 below.

\subsection{Table 4.7: The psychological interventions among amputees in Mulago specialized national hospital, Kampala-Uganda}

\section{Source: Primary 2019}

Findings in table 4.5 above shows specialized physicians as the most satisfactorily provided psychological interventions among amputees in Mulago specialized national hospital 36(60.0\%). This was closely followed by the other psychological intervention provided specifically primary care provision which was indicated by the majority of the amputees as satisfactory $27(45.0 \%)$

The results in table 4.5 above indicate financial assistance $28(46.7 \%)$ and also therapy providers $16(26.7 \%)$ as the satisfactorily provided psychological interventions among amputees in Mulago specialized national hospital. The study findings as per table 4.5 above shows support groups as the other psychologi- 
cal intervention provided to the amputees in Mulago specialized national hospital rated as poor by the majority $18(30.0 \%)$ but with a significant proportion of them indicating it as satisfactory $16(26.7 \%)$.

The study findings also show counseling services as the other psychological interventions provided among amputees in Mulago specialized national hospital but reported as poor by the majority $28(46.7 \%)$. This result show how much gap exists in as far as improving the counseling services are concerned and is suggestive of the need for improvement programmes in this regard.

\section{DISCUSSION, CONCLUSION, AND RECOMMENDATIONS \\ 6 Discussion of the findings}

The personality styles that enhance coping among amputees in Mulago specialized national hospital, Kampala-Uganda

The current study established openness and neuroticism as not being statistically significant correlates that enhance coping styles amputees in Mulago specialized national hospital $(p>0.05)$. This study however found extraversion as a personality style has got a statistically positive correlate with the confrontational form of coping style demonstrated among the respondent amputees $(r=0.279, p=0.031<0.05)$. The latter results are similar to one earlier established by (Lazarus et al.,1980) that emotion-focused coping within a person-environment relationship was altered by instrumental actions.

The results in this study also showed that agreeableness as a personality style had a significantly positive correlate that enhanced planful problem solving $(r=0.278, p=0.032<0.05)$ and positive reappraisal $(r=0.301, p=0.019<0.05)$ as a coping strategy. These results are much comparable to those established by (Rianne et al.,2014) just like Lakkin and Knowlton (2015) who found a significant role that social networks played in facilitating coping.

This study in addition found conscientiousness as a negative correlate of coping styles particularly self-control $(r=-0.326, p=0.011<0.05)$ and escape avoidance (Lazarus et al.,1980) that the relationship between the person and environment evolves as a result of a dynamic interplay between coping strategies, changes in the environment, and changes in the individual.

The psychological consequences among amputees in Mulago specialized national hospital, KampalaUganda

This study established the psychological consequences among amputees as abnormal depression $(46.7 \%)$ and suffering abnormal anxiety (45.0\%). These results are much similar to those earlier established by (Ziad et al.,2008) just as Srahbzu et al., (2017) that after an amputation the prevalence of depression and anxiety is as high as 41 percent. The results equally compare well with those earlier established by Sahu et al., (2016) that amputations are associated with a significantly decreased quality of life compared to lower extremity amputations because of substantial functional defects. These results are similarly comparable to those by Rybarczyk et al. (1992) that amputation is associated with depression, anxiety, and disturbed body image.

The current study also found the psychological consequences among amputees as demonstrating symptoms of at least 2 Post-Traumatic Stress Disorders (46.7\%) and symptoms of at least 1 Post-Traumatic Stress Disorder (18.3\%). These findings are much similar to those established by (Mountany et al., 2009) that the use of prostheses and orthosises in both lower and upper limb amputees can lead to restlessness and also post-traumatic stress disorder among others. These are similarly comparable to those earlier established by Atherton and Robertson (2006) that amputation can trigger psychological distress in an individual. They are also similar to those by Mischel et al.,(2014) who found experiencing trauma as resulting in the development of PTSD.

The psychological interventions among amputees in Mulago specialized national hospital, KampalaUganda

The current study found psychological interventions towards the amputees in Mulago Specialized hospital as specialized physician services (60.0\%), primary care provision (45.0\%), and financial assistance (46.7\%). This study established the other psychological interventions as therapy provision (26.7\%), support groups (26.7\%) alongside counseling services but reported as poor by the majority $28(46.7 \%)$. These 
results are quite comparable to those earlier established by Srivastava (2010) that family therapy may be indicated to assist in reaching the proper balance between the legitimate support amputees need and the independence that they must regain. The current findings are as well similar to those earlier established by (Rianne et al.,2014) who found a significant role that social networks play in facilitating coping.

\section{Conclusions}

The personality styles of extraversion, agreeableness, and conscientiousness are crucial in the coping styles demonstrated amongst individuals who have had traumatic experiences and therefore need to be well established and aligned supporting amputees.

The amputees who have had traumatic experiences are bound to suffer abnormal depression, anxiety with at least 1 or 2 Post-Traumatic Stress Disorders that need to be controlled in supporting the patients' wellbeing.

The psychological interventions particularly specialized physician services, primary care provision, financial assistance, therapy provision, and support groups are crucial in enhancing the wellbeing of the amputees that need to be supplemented with satisfactory counseling services.

\section{Recommendations}

Basing on the study objective, the study recommends health care providers in collaboration with the caregivers to institute mechanisms which help the amputees learn the approaches to embracing positive thinking about their present situations as minimizing the negative psychological consequences.

The administrative staff of specialized units needs to put in place workable measures like avoiding unfair self-blame and inculcating a belief that they are still worth as to help amputees to improve their self-esteem thereby minimizing adverse psychological consequences

The management of psychological consequences such as depression, anxiety, and PTSD after amputation needs to be incorporated in the services provided to patients so as to enable them to cope comprehensively despite the challenges they go through.

The clinicians extending care to amputees need to seek training programs that improve their counseling support skills if they are to contribute significantly to improving patients' wellbeing at satisfactory levels.

\section{Suggestions for Further Research}

The current study was carried out in only Mulago Specialized national hospital, Kampala-Uganda. The results would vary if other hospitals were to be involved. In addition, a bigger sample would be attained resulting in more generalizable findings. It is therefore recommended that future studies consider a census if not more health units and individuals that have had traumatic experiences.

The current study made use of quantitative research approaches only which does not bring out why some results are the way they are. It is thus recommended that future studies consider triangulating quantitative with qualitative research approaches like focus group discussion or interviews for clearer views based on in-depth opinions.

\section{Acknowledgements}

I acknowledge Mr. David Serunjogi for his Medical editorial work that he has done in this work through all stages of its development.

\section{References}

[1] A Barry Deathe and William C Miller. The L Test of Functional Mobility: Measurement Properties of a Modified Version of the Timed “Up \& Go" Test Designed for People With Lower-Limb Amputations. Physical Therapy, 85(7):626-635, 2005. 
[2] Y Dai, S Zhang, J Yamamoto, M Ao, T R Belin, and F Cheung. Cognitive behavioral therapy of minor depressive symptoms in elderly Chinese Americans: A pilot study. Community Ment Health J, 35:537579, 1999.

[3] S Folkman and R S Lazarus. An analysis of coping in an adequately functioning middle-aged community sample. J Health Soc Behav, 21:219-239, 1980.

[4] Kathryn Ziegler-Graham, Ellen J. MacKenzie, Patti L. Ephraim, Thomas G. Travison, and Ron Brookmeyer. Estimating the Prevalence of Limb Loss in the United States: 2005 to 2050. Archives of Physical Medicine and Rehabilitation, 89(3):422-429, 2008.

[5] M F Hilton. The Association Between Mental Disorders and Productivity in Treated and Untreated Employees. Journal of Occupational and Environmental Medicine, 51(9):996-1003, 2009.

[6] K A Raichle, M A Hanley, I Molton, N J Kadel, K Campbell, E Phelps, D Ehde, and D G Smith. Prosthesis use in persons with lower- and upper-limb amputation. Journal of rehabilitation research and development, 45:961-961, 2008.

[7] E Y Tay, J Jim, and A Nather, 2015.

[8] A D Abbas and A M Musa. Changing pattern fro extremity amputations in University of Maiduguri Teaching Hospital, Nigeria. Nigerian Journal of Medicine, 16(4):330-333, 2008.

[9] Angela D Ferguson, Beth Sperber Richie, and Maria J Gomez. Psychological factors after traumatic amputation in landmine survivors: The bridge between physical healing and full recovery. Disability and Rehabilitation, 26(14-15):931-938, 2004.

[10] L W Friedmann. The Psychological Rehabilitation of the Amputee. Springfield III, Charles C Thomas Publishers, 1978.

[11] J P Feighner, E Robins, S B Guze, R A Woodruff, G Winokur, and R Munoz. Diagnostic Criteria for Use in Psychiatric Research. Arch Gen Psychiatry, 26:57-63, 1972.

[12] M J E Neil. Pain after amputation. BJA Educ, 16:107-112, 2016.

[13] Jesus Montero-Marin, Javier Prado-Abril, Marcelo Marcos Piva Demarzo, Santiago Gascon, and Javier García-Campayo. Coping with Stress and Types of Burnout: Explanatory Power of Different Coping Strategies. PLOS ONE, 9(2):e89090-e89090, 2014.

[14] L Esguerra, 2016.

[15] J Beckman, M Creager, and P Libby. Diabetes and atherosclerosis: epidemiology, pathophysiology, and management. J Am Med Assoc, 287:2570-2581, 2002.

[16] R Seymour, 2002.

[17] Rajesh Sagar, Anamika Sahu, Rishab Gupta, Sushma Sagar, and Mohit Kumar. A study of psychiatric comorbidity after traumatic limb amputation: A neglected entity. Industrial Psychiatry Journal, 26(2):228-228, 2017.

[18] RUTH A. PARSLOW, ANTHONY F. JORM, and HELEN CHRISTENSEN. Associations of pre-trauma attributes and trauma exposure with screening positive for PTSD: analysis of a community-based study of 2085 young adults. Psychological Medicine, 36(3):387-395, 2006.

[19] A B Newman, D S Siscovick, T A Manolio, J Polak, L P Fried, N O Borhani, and S K Wolfson. Ankle-arm index as a marker of atherosclerosis in the Cardiovascular Health Study. Cardiovascular Heart Study (CHS) Collaborative Research Group. Circulation, 88(3):837-845, 1993. 
[20] H Ghamari Givi, A Zahed, D Fathi, , and and. Effectiveness of Group Cognitive-Behavioral Therapy on Depression among the Mournful Elderly. Journal of Geriatric Nursing, 2(3):22-31, 2016.

[21] C Sjödahl, G Gard, and G B Jarnlo. Coping after trans-femoral amputation due to trauma or tumour-a phenomenological approach. Disability and Rehabilitation, 26(14-15):851-861, 2004.

[22] N Arifin, H R Hasbollah, M H Hanafi, A H Ibrahim, W A W A Rahman, and R C Aziz. Provision of Prosthetic Services Following Lower Limb Amputation in Malaysia. Malays J Med Sci, 24:106-111, 2017.

[23] Kathryn Ziegler-Graham, Ellen J. MacKenzie, Patti L. Ephraim, Thomas G. Travison, and Ron Brookmeyer. Estimating the Prevalence of Limb Loss in the United States: 2005 to 2050. Archives of Physical Medicine and Rehabilitation, 89(3):422-429, 2008.

[24] M J Amalraj, A, A R Viswanathan, *, and V, 2017.

[25] ChibuzoU Ndukwu and ChigozieA Muoneme. Prevalence and pattern of major extremity amputation in a tertiary Hospital in Nnewi, South East Nigeria. Tropical Journal of Medical Research, 18(2):104-104, 2015.

[26] Susan Folkman and Richard S. Lazarus. If it changes it must be a process: Study of emotion and coping during three stages of a college examination. Journal of Personality and Social Psychology, 48(1):150-170, 1985.

[27] R S Lazarus and S Folkman. Stress Appraisal and Coping. Springer, New York, 1984.

[28] R E Stroke. Casestudies: In: Handbook Qualitative Research. In NK. Denzin and Lincoln, 1994.

[29] J R Kirkup, 2007.

[30] R Mountany, 2009.

[31] Jens Foell, Robin Bekrater-Bodmann, Herta Flor, and Jonathan Cole. Phantom Limb Pain After Lower Limb Trauma, 2011.

[32] Susan Folkman and Judith Tedlie Moskowitz. Coping: Pitfalls and Promise. Annual Review of Psychology, 55(1):745-774, 2004.

[33] Wolf Schweitzer, Michael J. Thali, and David Egger. Case-study of a user-driven prosthetic arm design: bionic hand versus customized body-powered technology in a highly demanding work environment. Journal of NeuroEngineering and Rehabilitation, 15(1), 2018.

[34] Kathryn E.S. Buikema and Jon H. Meyerle. Amputation stump: Privileged harbor for infections, tumors, and immune disorders. Clinics in Dermatology, 32(5):670-677, 2014.

[35] J Highsmith, J Kahle, T Klenow, C Andrews, K Lewis, R Bradley, .. Highsmith, and J, 2016.

[36] M L Mccarthy, E J Mackenzie, D Edwin, M J Bosse, R C Castillo, A Starr, J F Kellam, A R Burgess, L X Webb, M F Swiontkowski, R W Sanders, A L Jones, M P Mcandrew, and B M Patterson, 2003.

[37] J Hay, R Morris-Jones, \&amp; R, and \&amp; 2010.

[38] Susan Folkman and Richard S. Lazarus. An Analysis of Coping in a Middle-Aged Community Sample. Journal of Health and Social Behavior, 21(3):219-219, 1980.

[39] S Merrian. Qualitative Research and Casestudy Applications in Education. Jossey Bass Publishers, SanFrancisco, 1998.

[40] Chaya G. Bhuvaneswar, Lucy A. Epstein, and Theodore A. Stern. Reactions to Amputation: Recognition and Treatment. The Primary Care Companion to The Journal of Clinical Psychiatry, 09(04):303-308, 2007.

[41] K S Dobson, 2009. 
[42] RIANNE DEKKER and GODFRIED ENGBERSEN. How social media transform migrant networks and facilitate migration. Global Networks, 14(4):401-418, 2014.

[43] Linda ; Brannon and Jess Feist. Personal Coping Strategies". Health Psychology: An Introduction to Behavior and Health: An Introduction to Behavior and Health. Wadsworth Cengage Learning, pages 121-124, 2009.

[44] C. H. Tseng. Prevalence of lower-extremity amputation among patients with diabetes mellitus: Is height a factor? Canadian Medical Association Journal, 174(3):319-323, 2006.

[45] A. Salawu, C. Middleton, A. Gilbertson, K. Kodavali, and V. Neumann. Stump Ulcers and Continued Prosthetic Limb Use. Prosthetics and Orthotics International, 30(3):279-285, 2006.

[46] J E Onuminya, P O Obekpa, H C Ihezue, N D Ukegbu, and B O Onabowale. Major Amputations in Nigeria: A Plea to Educate Traditional Bone Setters. Tropical Doctor, 30(3):133-135, 2000.

[47] Stephanie Huang and Daniel P Ferris. Muscle activation patterns during walking from transtibial amputees recorded within the residual limb-prosthetic interface. Journal of NeuroEngineering and Rehabilitation, 9(1):55-55, 2012.

[48] Chioma Unachukwu, Seye Babatunde, and Anele E. Ihekwaba. Diabetes, hand and/or foot ulcers: A cross-sectional hospital-based study in Port Harcourt, Nigeria. Diabetes Research and Clinical Practice, 75(2):148-152, 2007.

[49] R. Jiménez-Fabián and O. Verlinden. Review of control algorithms for robotic ankle systems in lower-limb orthoses, prostheses, and exoskeletons. Medical Engineering \& Physics, 34(4):397-408, 2012.

[50] P. W. Moxey, P. Gogalniceanu, R. J. Hinchliffe, I. M. Loftus, K. J. Jones, M. M. Thompson, and P. J. Holt. Lower extremity amputations - a review of global variability in incidence. Diabetic Medicine, 28(10):1144-1153, 2011.

[51] Eric Edison Low, Elizabeth Inkellis, and Saam Morshed. Complications and revision amputation following trauma-related lower limb loss. Injury, 48(2):364-370, 2017.

[52] Steven Ovadia and Morad Askari. Upper Extremity Amputations and Prosthetics. Seminars in Plastic Surgery, 29(01):055-061, 2015.

[53] Jonatan Tillander, Kerstin Hagberg, Lars Hagberg, and Rickard Brånemark. Osseointegrated Titanium Implants for Limb Prostheses Attachments: Infectious Complications. Clinical Orthopaedics and Related Research $^{\circledR}, 468(10): 2781-2788,2010$.

[54] TIMOTHY R. DILLINGHAM, LILIANA E. PEZZIN, and ELLEN J. MACKENZIE. Limb Amputation and Limb Deficiency: Epidemiology and Recent Trends in the United States. Southern Medical Journal, 95(8):875-883, 2002.

[55] H Ghamari Givi, A Zahed, D Fathi, , and and. Effectiveness of Group Cognitive-Behavioral Therapy on Depression among the Mournful Elderly. Journal of Geriatric Nursing, 2(3):22-31, 2016.

[56] Kakra; Hughes and Sehgal. Rracial/ethnic Disparities in Lower Extremity Amputation Vs Revascularization: A Brief Review. Journal of the National Medical Association, 110:560-563, 2018.

[57] Troels S. Jensen, Børge Krebs, Jørn Nielsen, and Peter Rasmussen. Immediate and long-term phantom limb pain in amputees: Incidence, clinical characteristics and relationship to pre-amputation limb pain. Pain, 21(3):267-278, 1985.

[58] Daxing Wu, Huifang Yin, Shujing $X u$, and Ying Zhao. Risk factors for posttraumatic stress reactions among chinese students following exposure to a snowstorm disaster. BMC Public Health, 11(1):96-96, 2011. 
[59] H Wain, B Schneider, M L Dichtel, K N Benevides, R J Ursano, Walter Reed National, Military, Center, and Md, 2014.

[60] Cynthia L. Bartus and David J. Margolis. Reducing the incidence of foot ulceration and amputation in diabetes. Current Diabetes Reports, 4(6):413-418, 2004.

[61] Jan Gessmann, Mustafa Citak, Tobias Fehmer, Thomas Armin Schildhauer, and Dominik Seybold. Ilizarov External Frame Technique for Pirogoff Amputations With Ankle Disarticulation and Tibiocalcaneal Fusion. Foot \& Ankle International, 34(6):856-864, 2013.

[62] Susan Folkman and Richard S. Lazarus. An Analysis of Coping in a Middle-Aged Community Sample. Journal of Health and Social Behavior, 21(3):219-219, 1980.

[63] Matthew Jacofsky, 2011.

[64] P R Lewis, 2012.

[65] Julius A. Ogeng'o, Moses M. Obimbo, and John King'ori. Pattern of limb amputation in a Kenyan rural hospital. International Orthopaedics, 33(5):1449-1453, 2009.

[66] J L Parker. Aeromonas spp. clinical microbiology and disease. Journal of Infection, 62(2):109-118, 2011.

[67] Christine E. Agaibi and John P. Wilson. Trauma, PTSD, and Resilience. Trauma, Violence, \& Abuse, 6(3):195-216, 2005.

[68] C M Parkes. Factors determining the persistence of phantom pain in the amputee. Journal of Psychosomatic Research, 17:97-108, 1973.

[69] Chaya G. Bhuvaneswar, Lucy A. Epstein, and Theodore A. Stern. Reactions to Amputation: Recognition and Treatment. The Primary Care Companion to The Journal of Clinical Psychiatry, 09(04):303-308, 2007.

[70] Paul T. Costa and Robert R. McCrae. The Five-Factor Model of Personality and Its Relevance to Personality Disorders. Journal of Personality Disorders, 6(4):343-359, 1992.

[71] Linda Resnik, Marissa R. Meucci, Shana Lieberman-Klinger, Christopher Fantini, Debra L. Kelty, Roxanne Disla, and Nicole Sasson. Advanced Upper Limb Prosthetic Devices: Implications for Upper Limb Prosthetic Rehabilitation, 2012.

[72] Ziad Hawamdeh. Assessment of anxiety and depression after lower limb amputation in Jordanian patients. Neuropsychiatric Disease and Treatment, 4:627-627, 2008.

[73] R A Dieter, G B Kuzycz, and R A Dieter, 2017.

[74] Parkes Em. Determinants of disablement after loss of a limb. In Krueger DW, editor, Emotional Rehabilitation of Physical Trauma and Disability, pages 105-111, 1984.

[75] B Turney, S Kent, R Walker, and I Loftus. Amputations: no longer the end of the road. J R Coll Surg Edinb, 46:271-274.

[76] C K Onwukamuche. Fabrication of a Post-Operative Prosthesis - Quality of Life among Lower-Limb Prosthesis users in South-Eastern Nigeria. Owerri, 2018.

[77] R S Lazarus. Emotion and Adaptation. Oxford University Press, London, 1991.

[78] Walter Mischel. Toward an Integrative Science of the Person. Annual Review of Psychology, 55(1):1-22, 2004. 